\title{
DA CRIANÇA APRESENTADA NO EMÍLIO AO HIPOTÉTICO HOMEM NATURAL DO DISCURSO DA DESIGUALDADE: APROXIMAÇÕES A PARTIR DO VIÉS DA LINGUAGEM DO ENSAIO SOBRE A ORIGEM DAS LÍNGUAS
}

\author{
[FROM THE CHILD PRESENTED IN EMILIO TO THE HYPOTHETICAL NATURAL MAN OF THE \\ DISCOURSE OF INEQUALITY: APPROXIMATIONS FROM THE LANGUAGE BIAS OF THE ESSAY ON \\ THE ORIGIN OF LANGUAGES] \\ Luciano da Silva Façanha* \\ Francyhélia Benedita Mendes Sousa ** \\ XXX, XXX
}

\begin{abstract}
Resumo: Pesquisa de natureza teórica que investiga a Filosofia, a Educação e a Linguagem no pensamento de Jean-Jacques Rousseau (1712-1778). Com base nas obras Ensaio sobre a origem das línguas no qual se fala da melodia e da imitação musical; Discurso sobre a origem e os fundamentos da desigualdade entre os homens (1755) e Emílio ou Da Educação (1762), objetiva-se fazer uma análise da criança apresentada no Emílio por meio de analogias com o hipotético homem natural apresentado no Discurso sobre a desigualdade, a partir do viés da linguagem do Ensaio; bem como examinar o desenvolvimento da linguagem nos referidos personagens a partir da relação com a educação do Emílio. A pesquisa de caráter interdisciplinar apresenta como resultado a conclusão que a relação entre filosofia, linguagem e educação é uma interpretação fecunda para se compreender o pensamento rousseauniano.
\end{abstract}

Palavras-Chave: Filosofia; Linguagem; Educação; Natureza; Perfectibilidade
ABSTRACT: Research of a theoretical nature that investigates Philosophy, Education and Language in the thought of Jean-Jacques Rousseau (1712-1778). Based on the works Essay on the origin of the languages in which melody and musical imitation is spoken; Discourse on the origin and foundations of inequality between men (1755) and Emilio or Education (1762), aims to make an analysis of the child presented in Emilio through analogies with the hypothetical natural man presented in the Discourse on inequality, from the bias of the essay language; as well as examining the development of language in these characters from the relationship with Emilio's education. The interdisciplinary research presents as a result the conclusion that the relationship between philosophy, language and education is a fruitful interpretation to understand Rousseaunian thought.

KEYWORDS: Philosophy; language; education; nature; Perfectibility

\section{INTRODUÇÃO}

Tean-Jacques Rousseau (1712-1778) tem uma notável preocupação com a $\mathcal{J}$ origem das questões fundamentais do seu sistema1x, pois, segundo ele, seria necessário bem desenvolver por toda parte as primeiras causas para sentir o encadeamento dos efeitos (ROUSSEAU, 1948). Nesse sentido, "a reflexão sobre a linguagem ocupa, em Rousseau, um lugar considerável”' (STAROBINSKI, 2011, p. 409), podendo ser analisada a partir da perspectiva genealógica tanto no Discurso sobre a

* Doutor em Filosofia pela Pontifícia Universidade Católica de São Paulo. Professor permanente do Programa de Pós-graduação em Cultura e Sociedade - Mestrado Interdisciplinar (PPGCult), da Universidade Federal do Maranhão. Email: luciano.facanha@ufma.br. ** Mestranda do Programa de Pós-Graduação em Cultura e Sociedade (PGCult - UFMA). Bolsista da Fundação de Amparo à Pesquisa e ao Desenvolvimento Científico e Tecnológico do Maranhão (FAPEMA). Email: francyhelia.benedita@discente.ufma.br 
origem e os fundamentos da desigualdade entre os homens (1755) quanto no Ensaio sobre a origem das línguas na qual se fala da melodia e da imitação musical 2x. Apesar da interrogação sobre a origem das línguas configurar um esforço elementar nas referidas obras, é no Discurso sobre as ciências e as artes (1749) que o genebrino esboça as primeiras preocupações sobre o tema3x.

Nas obras que fundamentam sua teoria social, Rousseau desenvolve ideias mais radicais às quais apresenta no Segundo Discurso no qual o filósofo de Genebra aponta evidências de que as ciências e as artes não só não contribuíram para o aprimoramento dos costumes, porém ajudaram na sua degeneração4x, afastando-se consideravelmente das ideias postas pela filosofia iluminista setecentista. No Discurso sobre a desigualdade e Ensaio sobre a origem das línguas, o autor aponta para uma sociabilidade não natural (CASSIRER, 1992), ao afirmar que a sociedade não é algo necessário para o homem, mas uma contingência do acaso, de modo que poderia não ter sequer existido sociedade instituída. O mesmo processo contingente ocorre com a linguagem da convenção: "inclino-me, por isso, a pensar que, se sempre conhecêssemos tão-só necessidades físicas, bem poderiamos jamais ter falado, e entender-nos-iamos perfeitamente apenas pela linguagem dos gestos" (ROUSSEAU, 1798c, p. 162). A história conjectural exposta em ambas as obras, ilustra o estado original do homem. Nesse estado, suas únicas necessidades naturais são as de auto conservação. Portanto o homem das primeiras eras não necessitava do comércio com seus semelhantes, menos ainda do intermédio da palavra para se satisfazer.

Nesse sentido, Rousseau foi levado a tratar da linguagem não apenas no estado hipotético e histórico, como também no estado social. Relacionando linguagem e educação, o filósofo se ocupa com o tipo de linguagem que o homem desenvolve desde os seus primeiros anos de vida. A preocupação central desse desenvolvimento tem sua culminância no Discurso sobre a desigualdade: a linguagem chegou a tal ponto de degeneração, sendo usada para legitimar o discurso do grande malfeitor que, fazendo uso do "meu" conseguiu destituir o "nosso", sem que fosse desmascarado a tempo (ROUSSEAU, 1978b, p. 259). A legitimação da desigualdade pela linguagem é apenas uma das etapas de um extenso ciclo da perfectibilidade da linguagem, ciclo este que vai do estado silencioso do homem natural à condição de silenciamento imposta pela mais violenta desigualdade, levando Rousseau à conclusão, pela própria via da linguagem, que o primeiro contrato social falhou tendo a participação fundamental da "palavra nefasta" (STAROBINSKI, 2011, p. 418). A pergunta fundamental a se fazer a partir de tais conclusões filosóficas é: o homem degenerou, a sociedade degenerou, a linguagem degenerou, mas será sempre assim? Todo desenvolvimento humano sempre culminará em degeneração? Toda língua natural tenderá a ser uma linguagem nefasta? E o indivíduo, sempre cairá no abismo da vaidade e da decadência social?

Aliando teoria social a especulações político-pedagógicas Rousseau nos indica que não. Há uma alternativa. A educação enquanto formadora do indivíduo pode cumprir esse árduo objetivo. Apostando na interpretação narrativa da educação como a única alternativa possivel, capaz de dissolver a tensão entre natureza e cultura, Dalbosco aponta que "o diagnóstico pessimista do Segundo Discurso é corrigido pela arquitetônica pedagógica do Emílio” (2016, p. 49). Significando isso que, dependendo da forma com que o indivíduo seja formado, dependendo da educação que ele receba, sua desnaturação, apesar de inevitável, não resultaria em uma degeneração absoluta5x.

A relação comparativa entre a teoria social e a teoria educacional; entre a hipótese explicativa e a exemplificação da natureza não desfigurada, para além de um mero recorte no pensamento de Jean-Jacques Rousseau, tal interpretação analógica se configura como uma aproximação necessária. Uma vez que não é possivel estabelecer parâmetros para a educação do indivíduo social, se não se conhece o homem moderno. Por sua vez, "não se pode compreender o homem moderno se não se conhece a sociedade que o educou e não se pode compreender a sociedade se se ignora a maneira 
pela qual se constituiu" (STAROBINSKI, 2011, p. 392-3). Dessa maneira, o percurso da análise da história hipotética ao projeto político educacional é orientado por desejos da mesma ordem, são eles: conhecer o estado original, entender por quais razões o homem abdicou do equilíbrio natural lançando-se no devir da história negativa; o que ou quais fatores fizeram o homem sair do estado silencioso e o que possibilitou o empreendimento das artes? Só então, segundo Rousseau, pôde-se deduzir o que havia de necessário na natureza humana6x e o que a educação poderá conservar do estado original no indivíduo, desenvolvendo as potencialidades da criança no limite de suas forças a partir da condução conveniente e responsável do educando, pelo preceptor.

\section{O DESENVOLVIMENTO DA LINGUAGEM DO HIPOTÉTICO HOMEM NATURAL DO SEGUNDO Discurso}

Perturbado por indagações acerca da origem e o desenvolvimento da linguagem do hipotético homem primitivo, Rousseau questiona-se: por quais motivos o homem silencioso das florestas se poria a falar, não tendo necessidade da palavra para suprir suas necessidades mais urgentes? Diante de tais indagações, o filósofo de Genebra destaca duas dificuldades elementares quanto à formação da linguagem. A primeira: "como elas puderam tornar-se necessárias, pois, não tendo os homens qualquer correspondência entre si, nem necessidade alguma de tê-la, não se conceberia nem a sua necessidade dessa invenção nem a sua possibilidade se não fora indispensável" (ROUSSEAU, 1978b, p. 247).

Quanto a primeira dificuldade, Rousseau responde que a necessidade é suscitada pelo filho selvagem que tendo todas as suas necessidades para comunicar à mãe "deveu fazer os maiores esforços de invenção e a língua empregada por ele, em grande parte deve ser obra sua" uma vez que ele não adquiriu de outro, e multiplicando "as línguas em tantas quantos indivíduos houver para falá-las" (ROUSSEAU, 1978b, p. 247). Mas logo que cresce e se apossa da vida errante na natureza, o selvagem dispersa do grupo não dando tempo de haver uma língua consistente. Se instala aqui uma "nova dificuldade, pior ainda do que a precedente, pois, se os homens tiveram necessidade da palavra para aprender a pensar, tiveram muito mais necessidade ainda de saber pensar para encontrar a arte da palavra" [...] (ROUSSEAU, 1978b, p. 247).

Sobre a segunda dificuldade e suas consequências o genebrino elabora uma análise que o afasta totalmente de uma concepção metafísica da linguagem $7 x$. Seguindo uma linha que se aproxima mais do empirismo, porém bastante peculiar, Rousseau expõe que os primeiros nomes foram tropos; nomes particulares com ideias transpostas pelos sentidos que lhes davam, antes de conhecerem a propriedade das coisas, antes de reconhecê-las e significá-las por aquilo que eram e não por aquilo que a paixão oferecia aos olhos. Tal reconhecimento só pôde ocorrer após várias experiências ao longo das eras. Por mais que o selvagem tivesse a ideia de gigante, foi somente através das variadas experiências que a simples ideia surgiu em seu espírito, sendo necessário muitas outras sensações ainda para que sua imaginação ativasse e raciocinando por comparação, chegasse à ideia de homem fazendo-o perceber o equívoco inicial.

Nesse sentido, a primeira língua do homem é o grito da natureza. Caracterizada como uma linguagem de ação, a lingua natural é uma língua imperfeita e grosseira; acrescenta-se raras articulações e elementos convencionais, portanto "[...] é desprovida de meios lógicos, não contém funções gramaticais distintas; não se apresenta à abstração" (STAROBINSKI, 2011, p. 420). A língua universal dos homens primitivos, não é racionada, pelo contrário, é viva e figurada. "Apresentam-nos a linguagem dos primeiros homens como línguas de geômetras e verificamos que são línguas de poetas" (ROUSSEAU, 1978c, p. 163). O abismo da teoria rousseauniana referente às demais teorias da linguagem é eminente. "[...] Como o precursor de toda a nova reflexão 
sobre a linguagem e sobre as relações entre natureza e cultura" (PRADO JR, 2008, p. 58), Rousseau abandona uma concepção de linguagem logocêntrica. O que vai lhe interessar é concatenar o desenvolvimento da comunicação com fluxo das relações que o homem estabelece com o meio e os demais habitantes deste.

Ao longo do desenvolvimento teórico sobre a linguagem no Discurso sobre a 50 desigualdade, fica evidente a complexidade da análise da temática. O próprio autor se dá conta disso8x, como explica em nota, Arbousse-Bastide: "Rousseau compreende e confessa a dificuldade do problema da origem da linguagem, que continuará a preocupálo e que o levará ao Ensaio sobre o assunto" (1978b, p. 150). Publicado postumamente, O Ensaio sobre a origem das línguas: no que se fala da melodia e da imitação musical, tornou-se referência obrigatória para quem deseja entender sobre a configuração da linguagem no pensamento de Jean-Jacques Rousseau. Na obra, o filósofo se propõe a analisar e desenvolver as questões quanto à necessidade e a instituição da linguagem, as quais não foram esgotadas na obra sobre a desigualdade.

No Capitulo I do Ensaio Jean-Jacques lança mão da tese de que "pode-se, pois, crer que as necessidades ditam as os primeiros gestos e que as paixões arrancam as primeiras vozes (ROUSSEAU, 1978c, p. 163). Apresentar tal tese é afirmar que as necessidades não são a causa da saída do homem do estado de natureza para o estado de convenção da linguagem9x. Mais radical que isso, o crítico da Ilustração defende que a origem das línguas convencionadas não vem das necessidades, mas das paixões; enquanto que as línguas primitivas, ao contrário, originam-se da necessidade $1 x 0 x$. Reafirmando a tese central do Ensaio, Rousseau aponta "que, se sempre conhecêssemos tão-só necessidades físicas, bem poderíamos jamais ter falado, entender-nos-íamos perfeitamente apenas pela linguagem dos gestos" (ROUSSEAU, 1978c, p. 162-3). Se no estado de natureza primitivo o homem satisfaz suas necessidades sem o auxilio da palavra, por quais motivos as necessidades físicas haveriam de ser o motor do espirito humano para desenvolver a limitada comunicação existente?

Como tentativa de dissolução do problema Rousseau apresenta dois elementos fundamentais para sustentar sua tese sobre a origem das línguas. $\mathrm{O}$ primeiro refere-se à ideia na qual as necessidades não podem ser a causa da origem das línguas convencionadas. O segundo elemento, que não recebeu destaque no Discurso sobre a desigualdade, justamente pelo caráter universal da língua natural dos selvagens, é o fator geográfico. Este será preponderante para delimitar, consequentemente, determinar a origem das linguas. Sobre o primeiro elemento, verifica-se que as necessidades não podem ter sido a causa da origem das línguas, segundo Rousseau, uma vez que nas primeiras eras, elas afastavam os homens e não o contrário, deixando o questionamento sobre a origem da linguagem em aberto. Se as necessidades não têm o poder suficiente para fazer falar os homens, não têm a potência necessária para movimentar o espírito humano, assim, colocar em ação a perfectibilidade da linguagem, questiona-se o que teria a potência necessária para fazer mover o espírito de seu estado de equilíbrio ao estado da convenção social? O que ocorreu ao gênero humano que lhe fez querer, que fez desejar, que os despertou do estado de normalidade e indiferença? Colocando tais questões em uma, o cidadão de Genebra indaga: o que foi necessário, e quais fatores foram necessários para que o gênero humano começasse a sentir desejo e prazer onde antes existia indiferença?

Percebamos as sutilezas dos argumentos de Rousseau quanto à origem das línguas: a linguagem não pode ser filha das necessidades pois "os frutos não fogem de nossas mãos, é possível nutrir-se com eles sem falar” (ROUSSEAU, 1978c, p 164), mas para emocionar um jovem coração é necessário mais; é preciso externar o canto apaixonado. Mas persiste a questão posta como pano de fundo da argumentação: de onde veio a necessidade de emocionar um jovem coração? De onde surgem as paixões, ou melhor, quais foram as condições do surgimento das paixões, uma vez que elas são o motor da perfectibilidade da comunicação humana. 
A fim de responder a questão, o filósofo traz à cena o elemento geográfico, não apenas no interior da história da linguagem, mas como aspecto metodológico do próprio sistema. "O grande defeito dos europeus consiste em sempre filosofarem sobre as origens das coisas baseando-se no que se passa à sua volta" (ROUSSEAU, 1978c, p. 174) $1 \times 1 x$. O estudo do homem; a antropologia rousseuaniana está assentada sob a etnologia; diz-nos o filósofo, o homem que vamos estudar é oriundo de alguma região do globo. Sua localização, sua fixação geográfica, apresenta-se como fator primordial neste ponto da teoria da linguagem, uma vez que, para Rousseau, a região e o clima determinarão de qual homem estamos falando, determinará sua linguagem, pois antes já determinou suas paixões e suas necessidades. Conforme Prado Jr "é o próprio procedimento do conhecimento etnológico que é expresso nessa formula que nos mostra, para além do egocentrismo e da ingenuidade, que toda humanidade é local e que a universalidade só se encontra no sistema das diferenças" $(2008$, p. 63). O homem à esta altura no Ensaio, já não é mais primitivo, menos ainda hipotético, portanto, não podendo mais ser universal, já se apresenta como homem particularizado pela história, um homem determinado pela região que nasceu, condicionado pelo clima em que vive.

No primeiro estado, bebendo, comendo e dormindo a tempo e a hora, a locomoção dos primitivos deveu-se por motivos inteiramente naturais, para fugir das grandes intempéries naturais. "Nos primeiros tempos, os homens esparsos na superfície da terra não possuíam outra sociedade que não a da família, outras leis que não as da natureza, e por língua, apenas o gesto e alguns sons inarticulados" (ROUSSEAU, 1978c, p. 174). Dispersos pelas regiões, era necessário algo que os fizesse fixar em uma determinada região; a irregularidade da natureza os fez cultivar a terra, produzir seus alimentos, criar animais. Os primeiros povos "não habitavam regiões férteis ou margens acessiveis" e nessas regiões áridas, "nas quais só os poços forneciam água, tiveram de reunir-se para cavá-los, ou, pelo menos, combinarem seu uso" (ROUSSEAU, 1978c, p. 182). Quanto mais independentes, menos agrupados, quanto mais dependentes, mais necessitados. Isolados por muito tempo no interior de suas famílias, passaram todo esse período ignorando uns aos outros, até que as necessidades fizeram-lhes buscar a nutrição fora fazendo-os interagir uns com os outros, encontrando algo que no interior familiar não se distinguia. "As moças vinham procurar água para a casa, os moços para dar de beber aos rebanhos. Os olhos habituados desde a infância aos mesmos objetos começaram aí a ver outras coisas mais agradáveis" (ROUSSEAU, 1978c, p. 183) e a reunião entre os sexos deu-se primeiro pela necessidade, só depois pelas paixões: primeiro pela água, depois pelo amor.

As paixões nasceram do encontro entre os sexos. Com luzes mais desenvolvidas do que no estado primitivo, os viventes da vida selvagem começaram a distinguir objetos que outrora estava na total indiferença afetiva. "À medida, porém, que nos impressiona um objeto novo, queremos conhecê-lo e procuramos relações entre ele e o que já conhecemos" (ROUSSEAU, 1978c, p. 175). À medida que a água proporcionou os primeiros encontros entre os sexos, o desejo saltara aos olhos fazendo nascer as paixões e a necessidade de ser compreendido, a necessidade de falar de si e ser correspondido. Nesse processo, há o nascimento do amor próprio; a distinção entre o "outro" e o "eu" pela distinção do objeto que suscita no coração do homem o desejo de ser ele olhado ao passo que ele olha e sente a violência das paixões tomar para si o seu ser. Impelido por esses novos sentimentos, o homem histórico reconhecendo "outrem" como seu semelhante, reconhece o homem, e percebe ser ele um. Paralelamente, este é também o nascimento do indivíduo, que através desse reconhecimento, percebe-se como homem, sendo tomado pelo sentimento da preferência de si, desejando ele ser olhado de volta, pois agora "o gesto ardoroso não bastava e a voz o acompanhava com as acentuações apaixonadas; o prazer e o desejo confundidos faziam-se sentir ao mesmo tempo" (ROUSSEAU, 1978c, p. 183). É nítido, portanto, que o nascimento ou instituição da linguagem está intimamente ligado ao aparecimento do amor-próprio, 
assim como ao nascimento das nações; pois não pode existir sociedades sem linguagem instituída; as primeiras línguas são filhas do amor e os primeiros povos igualmente: "tal foi, enfim, o verdadeiro berço dos povos - do puro cristal das fontes sairam as primeiras chamas do amor" (ROUSSEAU, 1978c, p. 183). Por fim, respondendo à questão feita anteriormente, Rousseau demonstra que só o amor teve a potência necessária para desenvolver as línguas domésticas, convencionando-as em linguagem. Entendamos, que antes da revolução que as paixões proporcionam entre os grupos familiares "havia familias, mas não havia nações; havia línguas domésticas, mas nenhuma língua popular; havia casamentos, mas não amor" (ROUSSEAU, 1978c, p. 183).

$\mathrm{O}$ amor próprio, criando no espírito humano a necessidade de ser ele olhado e compreendido com a ternura que nunca o fora antes, suscita também a "palavra comum", que será o primeiro acordo instituido entre os grupos familiares distintos. Portanto, a língua nascente da reunião amorosa entre os sexos, será uma língua comum ao novo grupo, mais que isso, essa nova língua enriquecida pelo amor, passa agora ao status de linguagem, pois já não é mais a língua particular de uma família e menos ainda a lingua universal dos selvagens, porém é a palavra instituida pelo amor. Portando, as paixões, aliadas a ação, da perfectibilidade da comunicação, faz desenvolver a linguagem universal em línguas particulares, e estas em línguas comuns, e com isso, operando a conversão das línguas naturais em linguagem, ao que se deve a afirmação de Rousseau: "a palavra é a primeira instituição social” (ROUSSEAU, 1978c, p. 159). E sob o torpor das paixões e da ociosidade as primeiras palavras dos homens nas regiões quentes e áridas foi "amai-me", enquanto os povos setentrionais, laboriosos e preocupados, pois "sempre presente, o perigo de perecer não permitia que se limitassem à língua do gesto, entre eles a primeira palavra não foi amai-me, mas ajudai$m e^{\prime \prime}$ (ROUSSEAU, 1978c, p. 185).

\section{O DESENVOLVIMENTO DA LINGUAGEM DA CRIANÇA APRESENTADA NO EMÍLIO A PARTIR DA EDUCAÇÃO}

As preocupações de Jean-Jacques Rousseau com a comunicação do homem ultrapassam a origem e a instituição da linguagem, elas acompanham as diversas formas que a comunicação humana assumiu ao longo dos séculos. Rousseau foi levado a tratar da linguagem não apenas no estado hipotético e histórico, como também no estado social. Relacionando linguagem e educação, o filósofo se ocupa com o tipo de linguagem que o homem desenvolve desde os seus primeiros anos de vida.

No romance de formação, Emílio ou Da Educação $1 \times 2 x$, nos é apresentado Emílio. Este, não é um ser histórico ou factual, pois assim como seu preceptor e sua ama, ele não existe, não existiu e talvez, nunca existirá. Assim como a alma humana ainda não desfigurada pelos hábitos e costumes burgueses, Emílio é um personagem criado por Jean-Jacques Rousseau para refletir sobre a educação francesa que desconsiderava as especificidades da criança, e com isso negligenciava as etapas do desenvolvimento humano1x3x. Emílio, apesar de ser tomado como metáfora da alma humana não modificada, não é considerado por seu autor como um modelo universal ou conceito abstrato, ele é antes um protótipo do indivíduo moderno submetido a condições histórico-sociais e etnográficas $1 x 4 x$. Emílio é um aluno imaginário, ao qual Rousseau supõe sua idade, saúde, classe social, conhecimentos e todas as habilidades convenientes para trabalhar na sua educação. Disso segue a máxima: “a educação natural deve tornar um homem adaptável a todas as condições humanas” (ROUSSEAU, 1995, p. 29).

A educação de Emílio será uma educação doméstica. A educação doméstica ou da natureza, não formará seu aluno para exercer uma profissão ou representar qualquer outra cena burguesa decadente, pelo contrário, esta educação pretende formar o homem para a sua única e verdadeira condição, que é a de ser homem. No início da vida, 
começam as necessidades e o recém-nascido precisa de uma ama. Esta deve ser tão sadia de coração quanto de corpo; visando a boa alimentação do bebê. Rousseau, diz que a escolha da ama tem tanta importância, quanto a escolha da criança e do preceptor. "O bebê não deve ter outra governante senão sua ama, assim como não deve ter outro preceptor senão seu governante" (ROUSSEAU, 1995, p. 35).

Assim como o aluno e a ama, o governante1 $\times 5 \times$ deve ser muito bem escolhido, pois alerta o autor que "como pode ocorrer que uma criança seja bem educada por quem não o foi ele próprio?" (ROUSSEAU, 1995, p. 35). Portanto, o preceptor de Emílio deve ter também uma educação da natureza, pois será necessário que saiba interpretar seus sinais. Todas as regras e princípios que o preceptor deve seguir para com seu aluno estão inscritas na natureza da criança. Observar a natureza e seguir o caminho que ela vos indica. Observar o comportamento de seu aluno desde os primeiros gritos e gestos deve ser fundamental; "logo ao nascer apropriai-vos dele, não o largais antes que seja homem: nada conseguirei sem isto" (ROUSSEAU, 1995, p. 24).

O governante deve começar a observação pelas primeiras expressões do bebê, pois "os primeiros choros das crianças são solicitações: se não tomamos cuidado, logo se tomam ordens; começam pedindo assistência, acabam fazendo-se servir. [...] desde a primeira infância, importa descobrir a intenção secreta que dita o gosto ou o grito (ROUSSEAU, 1995, p. 47). Portanto, a primeira língua da criança é de solicitação; o choro e os gritos podem ser a expressão da necessidade ou as primeiras manifestações de domínio dos bebês. Em função disso, Rousseau ratifica a importância do cuidado com a criança na primeira infância, vigiar, conhecer, interpretar e cuidar da natureza da criança para que não se desencaminhe, é responsabilidade do preceptor. Este deve cuidar para que somente as necessidades sejam atendidas, nunca as solicitações supérfluas, do contrário tudo estará perdido1x6x. De modo que a primeira tarefa da educação natural ou da primeira educação é garantir a conservação da natureza da criança1x $7 \mathrm{x}$.

Assim, pois, na infância a ama é a interprete da fala dos bebês, pois sempre sabe o que lhes dizem e o preceptor é o interprete da natureza, pois deve saber compreender seus sinais. Cerizara aponta que "repleto de significados, o choro determina o modo de o bebê relacionar-se com o mundo. Por isso os adultos, ao lidarem com ele, devem tomar consciência dos seus aspectos" (1990, p. 67). Portanto, com os olhos e ouvidos atentos às primeiras vozes de Emílio, o preceptor deve preservar seu aluno, para que o império do hábito não se instale, pois a criança fazendo com que vos ocupeis da vontade dela torna-se senhora de vós e por consequência, torna-se escrava das próprias vontades. Disso decorre a quarta máxima da educação natural: "é preciso estudar com cuidado sua linguagem e seus sinais, a fim de que, numa idade em que não sabem dissimular, possamos distinguir em seus desejos o que vem imediatamente da natureza do que vem da opinião" (ROUSSEAU, 1995, p. 50).

Mas Rousseau assevera que o único hábito que se deve deixar a criança adquirir é o de não contrair nenhum. O preceptor deve conduzir "de longe o reinado de sua liberdade e o emprego de suas forças, deixando o seu corpo hábil natural, pondo-a em estado de ser sempre senhora de si mesma [...]" (ROUSSEAU, 1995, p. 43). Na fase inicial da criança, o genebrino aponta que ainda quando a memória e a imaginação são inativas, a criança só presta atenção àquilo que o afeta nos sentidos; sendo suas sensações o primeiro material de seus conhecimentos, oferecer-lhes numa ordem a seu entendimento. Aqui, temos a descrição do filósofo da natureza em relação aos primeiros contatos e apreensão da criança com o todo que o cerca. Percebamos que ela está em um lento processo de desenvolvimento dos sentidos e sensações, para que depois possam ser capturadas pela imaginação e memória e levadas ao entendimento, e assim quando necessário tenha os meios para suprir suas próprias necessidades. Por sua vez, estas necessidades, são expressas na infância pelos choros e gritos das crianças, "pois todas as suas sensações são afetivas, e quando são agradáveis elas apreciam em silêncio; quando penosas, elas o dizem em sua linguagem e pedem alivio" (ROUSSEAU, 1995, p. 45). 
Na primeira fase da vida que vai do 0 (zero) aos 2 (dois) anos, a infans, fase em que a criança ainda não pode falar, a língua sonora não é o único meio de expressar suas emoções e sensações, os choros e gritos juntam-se às expressões faciais e a cada sorriso, susto ou pavor que se manifestam nas fisionomias mal formadas dos bebês, o governante tem mais expressões para lhe auxiliar na interpretação das necessidades ou desejos dos pequenos. A primeira linguagem da criança são elas as expressões de queixas e choros, inarticuladas e sonoras, além dos gestos faciais que expressam seus primeiros sentimentos, mas que ainda não tem qualquer vestígio de sistematização, portanto de razão.

Com a ação da perfectibilidade no pequeno Emílio, seus choros e inquietações tendem a ser mais raros; logo será menos inquieto, mais fechado em si mesmo, posto o equilíbrio entre corpo e espírito, logo será um falante. A fase da infância muda, a linguagem a acompanha; a idade do choro dá lugar à idade da força. Com o progresso natural da linguagem, choram menos, imitam mais; os gritos são substituidos por vozes mais articuladas, se "podem dizer que sofrem com palavras, por que o diria com gritos?” (ROUSSEAU, 1995, p. 58). Querendo falar desde que nasceram, não o fazem, pois "nós lhes falamos, não somente antes que compreendam o que lhes dizemos", mas "antes que possam repetir os sons que ouvem" (ROUSSEAU, 1995, p. 52), e pior ainda é quando seus cuidadores querem que as crianças falem depressa, acabam por obter o efeito contrário. Erros recorrentes da educação dos moradores das cidades; o aluno da educação natural não terá tais vícios. Emílio será criado no campo, onde não se achando sempre perto de seu mestre, aprenderá a dizer muito nitidamente o que quer comunicarlhe. É preciso fazer-se entender ao falar, pois essa "é a primeira lei do discurso", diz o filósofo de Genebra. Cultivado sob a autenticidade campesina, o aluno tende a adquirir uma voz sonora, mas não poderá contrair as expressões e o tom de fala dos aldeões; será a partir desses hábitos que a criança falará um francês puro, distinto e bem articulado.

Começa então a segunda tarefa da educação ou a segunda fase fundamental da educação natural: a conversão ou instrução $1 x 8 x$. Em sendo "preciso que o hábito mude a natureza" (ROUSSEUA, 1995, p. 20) o governante deve cuidar da condução desse hábito. Com o progresso da comunicação, do sofrimento, das forças e das faculdades, a língua universal será substituída pela linguagem articulada; a convenção dos sinais, dos gestos, dos hábitos, e dos costumes, torna-se cada vez mais presente, e não só; torna-se necessário. $\mathrm{O}$ choro que antes era o elo entre a necessidade do bebê e seu interprete, será necessariamente substituida pela linguagem das palavras convencionais, serão elas a partir de agora que manterão a relação entre mestre, aluno e demais integrantes da cadeia social de Emílio.

O progresso da linguagem não é o único nesta fase da vida. "Podendo mais por si mesmas sentem necessidade menor de recorrer a outrem. Com sua força desenvolve-se o conhecimento que as põe em estado de dirigi-la" (ROUSSEAU, 19995, p. 60). Na fase da puer, que vai dos 02 (dois) aos 12 (doze) anos, a criança tende a tornar-se cada vez mais independente; pois é nesta fase que ela terá as primeiras lições de coragem. Com o desenvolvimento de seu corpo, é necessário que conheça a dor, pois sofrer é a primeira coisa que deverá aprender. O governante deve deixar que caia, que exercite seus membros, que corra, que brinque, que se machuque, que viva a liberdade de ser criança, pois "o bem-estar da liberdade compensa muitas machucaduras"1x9x (ROUSSEAU, 1995, p. 60).

Emílio está na idade de pleno desenvolvimento. A ação fatídica da primeira faculdade, pondo as demais em ato; desenvolvendo gradualmente as faculdades virtuais, e a imaginação, a mais ativa de todas, desperta e se coloca a frente das outras, pois desde quando nascem os pequenos já têm fantasias. É preciso então que o governante não as estimule; que mantenha seu aluno longe de fantasias, alerta Rousseau: "ó homem! Encerra tua existência dentro de ti e não serás mais miserável" (ROUSSEUA, 1995, p. 66); não te deixes convencer pelos falsos choros e caprichos; "não façais nenhuma 
concessão a seus desejos por que ela o pede e sim quando tiver necessidade disso" (ROUSSEUA, 1995, p. 69); é preciso, portanto, distinguir com muitíssimo cuidado as reais necessidades das fantasias.

A preocupação de Rousseau com esta fase da vida é nítida, posto que tantos são os vícios que as crianças podem contrair nesta fase. Em função disso, as instruções para o governante são expressas: "ó mestre, conservais seu aluno apenas nas dependências das coisas" (ROUSSEAU, 1995, p. 69); segue a sabedoria da natureza que determinando a máxima fundamental, considerou como "homem realmente livre aquele que só quer o que lhe apraz" (ROUSSEAU, 1995, p. 67); por isso, a felicidade de teu aluno depende da perfeita igualdade entre poder e vontade; não ultrapasse com ele os limites da realidade, "não ofereçais jamais a suas vontades indiscretas senão obstáculos físicos"; evitais também estimular palavras vãs a seu aluno; é preferível que Emílio "diga pedindo fazei-me isto a dizer-lhe ordenando, peço-vos". A palavra que ele utiliza é menos importante do que o sentido que lhe dá. "A primeira falsa ideia que entra em sua cabeça é germe do erro e do vício". Falando com ele sobre coisas que ele não conhece e pior, sobre coisas que ainda não pode compreender, estarás atingindo o objetivo oposto ao esperado, pois "falhando-lhe, desde a primeira infância, uma língua que não entende, acostumam-na a jogar com as palavras, a controlar tudo que lhe dizem" (ROUSSEAU, 1995 , p. 74); instruir-lhe por uma linguagem que não é conveniente, pior que isso, que é desconhecida à sua idade, é um caminho perigoso; é submeter seu espírito puro a vícios aos quais nem defender-se ele mesmo pode.

Dado tantos deveres incumbidos ao preceptor e com tantas dificuldades para obter êxito na educação de seu aluno, assim, na conservação da criança em suas necessidades e na condução da conversão de sua linguagem e de seus hábitos, Rousseau aponta o único instrumento, segundo ele, capaz de dar resultado no projeto educacional de Emílio. A liberdade bem regrada pretende ajuizar ambas as tarefas da educação natural, deixando a criança seguir o curso natural de seu desenvolvimento, mas também conduzindo tal liberdade dada, ao passo que não deve permitir que a criança tenha contato com a cultura burguesa vigente, até que esteja preparado para tal. Assim, ao mesmo tempo que preserva a criança da servidão civil, dar-lhe a liberdade necessária para sua maturação, dando a ela mais tempo e espaço para exercer seu direito de ser criança, a liberdade bem regrada conserva ainda o coração puro de contrair os males advindos da precoce instrução, às quais as crianças do século XVIII eram submetidas.

Portanto, a liberdade bem regrada opera em comum acordo com a educação negativa, visto que esta consiste em "negativar" em parte a cultura euro-ocidental2x0x, de modo a subtrair, ou ao menos afastar da instrução de Emílio até o momento oportuno, os costumes, os hábitos, os vícios, os excessos, os valores deturpados, o gosto refinado, os luxos, enfim, a degenerada exuberância da vida moderna; retardar a instrução dos conhecimentos e estudos das línguas, da história, das ciências e das literaturas. Portanto, trata-se menos "em ensinar a virtude e a verdade do que preservar o coração do vício e o espírito do erro" (ROUSSEAU, 1995, p. 80). Fazendo uso da liberdade bem regrada na instrução de Emílio, o verdadeiro governante saberá para onde quer levar seu aluno, qual objetivo pretende alcançar.

\section{AS APROXIMAÇÕES E DIFERENÇAS DA CRIANÇA E DO SELVAGEM A PARTIR DO VIÉS DA LINGUAGEM E DA EDUCAÇÃO}

Sendo a linguagem um dos aspectos humanos presentes ao longo de todo o processo de desnaturação, ela assume um papel fundamental nas pretensões rousseaunianas, possibilitando que se produza análises do percurso do homem na história através do estudo da comunicação humana desde seu estado original. Com isso, ao se analisar as figuras centrais da teoria social e da teoria educacional desde o estado 
zero de seu desenvolvimento, percebe-se aspectos distintos e similares entre as ilustrações da alma humana pura, interessando-nos neste terceiro ponto da investigação, concentrar os apontamentos na relação entre linguagem e educação.

Quando se faz a comparação entre o homem hipotético apresentado no Discurso sobre a origem e os fundamentos da desigualdade entre os homens e a criança do

56 Tratado de Educação a partir da linguagem e da educação, é possível perceber algumas diferenças e semelhanças. Ambos representam o estado natural do homem, que ainda com memória, imaginação e raciocinio inativos, são pura sensação, não possuindo até mesmo noção da própria existência. A primeira linguagem, melhor dizendo, a língua de ambos personagens conjecturais são sons inarticulados desprovidos de qualquer sistematização ou organização racional.

O homem do estado de natureza primitivo é uma hipótese explicativa que o filósofo usa para explicar como teria sido o homem em seu estado antissocial. Estado, esse em que ainda não haveria desigualdades de poder, mas apenas diferenças físicas. Descrito no Discurso sobre a desigualdade, ele tem tudo à sua disposição, a tempo e a hora, não necessitando de outros meios para satisfazer suas necessidades mais urgentes (ROUSSEAU, 1978b). É a luz desse raciocínio que Rousseau chega à conclusão que os primeiros homens não necessitavam fazer uso da palavra para atender às suas necessidades, no mais, apresentavam apenas sinais simples e visíveis. Uma vez que não teria contato duradouro com outros da espécie, não tinham residência estável, mas abrigavam-se em qualquer lugar e não mais do que umas noites: "os machos e as fêmeas uniam-se fortuitamente segundo o acaso, a ocasião e o desejo, sem que a palavra fosse um interprete necessário das coisas que tinham a dizer, e separavam-se com a mesma facilidade" (ROUSSEAU, 1978b, p. 247). Por conseguinte, no primeiro estado de natureza, o homem não apresentava sinais com a minima sistematização, senão sinais provenientes da sua própria condição animal. Como aponta Rousseau "a primeira língua do homem, a língua mais universal, a mais enérgica e a única de que se necessitou antes de precisar-se persuadir homens reunidos, é o grito da natureza" (ROUSSEAU, 1978b, p. 248); usada para pedir socorro nas horas de eminente perigo ou alivio das dores violentas da vida selvagem.

Aí está a primeira grande similaridade entre o homem hipotético e a criança do Emílio: "assim como Emílio, o primitivo natural é um infan, privado da palavra" (STAROBINSKI, 2011, p. 414). A primeira língua da criança, assim como a lingua do primitivo natural, é a voz da natureza que se manifesta por meio de gritos e choros. "Sendo sinais puramente animais, o grito da natureza se faz ouvir como um alerta de perigo ou de dor". Na criança essa voz natural expressa também as primeiras sensações de fome, frio e calor. A primeira forma de comunicação das crianças, assim como dos homens primitivos é a verdadeira língua universal. "Procura-se durante muito tempo saber se haveria uma língua natural e comum a todos os homens. Sem dúvida há uma: a que as crianças falam antes de saberem falar. Essa língua não é articulada, mas é acentuada, sonora e inteligível" (ROUSSEAU, 1995, p.45-6).

A língua natural dos selvagens e das crianças é universal, pois, todos os seus caracteres, sinais, gestos, gritos são formas imediatas de comunicação; elas se fazem compreender em todos os lugares e em todas as épocas, não precisam de nenhum interprete senão os olhos e ouvidos; possuem a vivacidade e potência que nenhuma língua articulada pode possuir. A perfectibilidade, entre outras causas, faz a língua universal dos primitivos e das crianças passar pelo processo de desnaturação, o que acarreta uma particularização da língua: cada caractere adquirido cada sinal, acentuação e entonação, destitui o aspecto universal da comunicação, pois assim como o gosto, quanto mais simples a língua, mais universal; serão menos relações para interpretar, a arte empregada para tornar as línguas modernas "refinadas", as tornou também surdas, morosas, sem vida, sem força, pior ainda, combinadas ao gosto e a relações corrompidas, as línguas tornaram-se adereços do luxo e do poder2x1x. 
É a partir da análise da língua natural que surge a primeira diferença entre Emílio e o homem primitivo: a dependência e a autossuficiência. Nessa relação, quando se compara a criança com o primitivo natural adulto, nota-se que este não precisa gritar ou chorar para se alimentar ou matar sua sede, mas apenas caminhar até o riacho mais próximo e pegar o fruto que está à altura da mão. Porém a criança é um ser totalmente dependente, fazendo uso da primeira língua não apenas como uma forma de expressar as primeiras sensações, mas também como uma forma de sobrevivência.

A primeira lingua tem um outro modo de fazer comunicar e entender um homem. A língua dos gestos e sinais visiveis, presente tanto no homem natural quanto na criança, é uma linguagem mais mediata do homem e com um alcance bem menor que os sinais sonoros, porém, "apesar de serem a linguagem do gesto e da voz igualmente naturais, a primeira, todavia, parece mais fácil e depende menos de convenções, porquanto um maior número de objetos impressiona antes os olhos do que nossos ouvidos" (ROUSSEAU, 1978c, p. 160). São também as mais verdadeiras as expressões corporais e faciais são mais dificeis de serem dissimuladas.

Mas com o passar de um longo período não mensurado pela história humana, o grito da natureza deu lugar a sinais mais sonoros, flexivos e com maior grau de organização. Por causas naturais diversas, como as secas ou tempestades, e outras intempéries naturais, o homem começa a agrupar-se com maior frequência e duração, precisando manter uma comunicação mais estável com os membros do grupo2x $2 x$. A comunicação segue o curso do desenvolvimento. A linguagem nasce e se desenvolve à medida que os indivíduos sentiram a necessidade de contar-lhes suas emoções a outros. "Na medida em que as necessidades crescem [físicas e morais], os negócios se complicam, as luzes se expandem, a linguagem muda de caráter (ROUSSEAU, 1978c, p. 167). A palavra, a voz das paixões, logo necessita de um conjunto maior de caracteres, fazendo nascer novas palavras, acentos e sinais. Portanto, a instituição da linguagem dar-se inexoravelmente à instituição da sociedade, visto que os grupos sociais necessitam de uma língua comum, e o desenvolvimento daqueles implica diretamente no desenvolvimento da linguagem.

A palavra, diferente da voz da natureza, é um elemento distinto para a criança e o primitivo. No homem natural, a linguagem tem sua origem na necessidade moral. Foram as paixões que arrancaram os homens de seu estado primitivo, fazendo-os falar. Mas a criança, pelo fato de não está no estado de natureza primitivo, não tem as primeiras vozes ditadas pelo ardor do ódio, da cólera ou do amor, mas é a necessidade que a faz falar. Uma vez que as paixões só deverão surgir na idade da razão, que vai dos 15 aos 20 anos de idade, não são elas as responsáveis pelas primeiras palavras de Emílio, senão a sua necessidade de comunicar suas dores e queixas. Fazendo-se necessário pontuar que em ambos os casos, o desenvolvimento da linguagem se dá de forma natural, a passagem de uma lingua menos sonora e articulada a uma linguagem menos visível e mediata é um progresso natural. Distintos quanto ao motor da linguagem, homem natural e Emilio, aproximam-se por aquilo que lhes permite a fala.

É certo, para Rousseau, que o homem não constitui linguagem apenas por que possui órgãos que facilitam sua fala; do contrário outros animais também o conseguiriam, mas estes possuem apenas línguas naturais como autômatos que obedecem somente às determinações da natureza. No entanto, não sendo um mero animal, menos ainda um autômato, o homem possui a faculdade de aperfeiçoamento de si mesmo. A perfectibilidade, aliada ao poder de consentir e recusar, isto é, aliada à liberdade, possibilita ao homem articular, flexionar e sistematizar seus signos e sua comunicação, constituindo formas de comunicação cada vez mais raciocinadas.

Nesse contexto, outro ponto fundamental a ser analisado por meio da analogia entre o Emílio e o primitivo natural é a capacidade de aperfeiçoamento de ambos. A perfectibilidade é apresentada textualmente por Rousseau pela primeira vez no Segundo Discurso, aparecendo também no Tratado de Educação. Ela é um elemento chave para a 
análise do desenvolvimento da linguagem nas referidas obras e personagens, pois é ela que dá sustentação à aproximação comparativa entre o hipotético homem natural do Segundo Discurso e a criança do Emílio, posto que "o ser humano não [detém] uma essência pronta que caminha para sua perfeição, mas é um ser de capacidades, às quais podem se desenvolver indefinidamente e para as mais variadas direções" (DALBOSCO, 2016, p. 121). Sendo a faculdade de desenvolvimento de si mesmo uma caracteristica presente tanto na espécie quanto no indivíduo, logo todos os indivíduos são perfectíveis, cada um à própria maneira; tanto Emilio quanto o homem natural são perfectíveis. A não determinação da natureza humana faz do homem um animal com capacidade para um aperfeiçoamento ilimitado e variado, por isso mesmo, o primeiro estado do homem é evolutivo. Portanto, a degeneração não é definitiva para a espécie, apenas para uma determinada sociedade em um dado momento histórico, visto que o individuo pode desenvolver-se nas mais variadas direções.

O homem natural, sem a mínima noção de formação $2 \times 3 x$, desenvolveu-se segundo o acaso, seguindo o percurso que as intempéries naturais lhe impuseram. Nesse sentido, quando se analisa a conexão entre homem natural e criança, verifica-se que a preocupação de Rousseau diz respeito à ação da perfectibilidade sobre a criança; o modo como suas faculdades virtuais serão desenvolvidas. Não é simplesmente com o progresso da fala que Rousseau se preocupa, porém, a maneira como o desenvolvimento ocorre na criança. Um dos motivos está ligado à representação: a "linguagem torna-se o veículo mais expressivo de sua capacidade de representação, sendo por meio dela que o homem pode exteriorizar-se, colocando-se mediante apreciação do juízo alheio, isto é, mediante o olhar público" (DALBOSCO, 2016, p. 59). Nesse sentido, a linguagem é uma representação, a palavra não é a coisa, mas a sua representação, por meio do qual ocorre a cisão no eu, dando a possibilidade ao falante de colocar-se fora de si mesmo; "colocar-se calculadamente, por meio da linguagem no lugar do outro, para usá-lo com fins de interesse próprio" (DALBOSCO, 2016, p. 59). A dissimulação da linguagem é um dos perigos que a perfectibilidade da comunicação traz ao homem $2 x 4 x$. Há aqui a afirmação da necessidade de uma educação que conduza o educando de forma conveniente e responsável. Emílio, distintamente do primitivo natural, já nasce no estado social, e por precisar ser inserido no meio social não precisará criar signos para designar os objetos que os cercam. Porém, será conduzido por meio de uma linguagem já instituída. Por conseguinte, a cultura em que Emílio viverá, advém de uma sociedade formada por desigualdades e vícios de variados tipos. Por já partilhar de uma herança cultural corrompida, o aluno precisará também ser guiado para que não seja traído pela própria cultura. Nesse sentido, a educação da criança deve ser uma educação negativa.

A criança ao nascer é pura determinação da natureza, mas vem com disposições para a sua orientação no mundo, assim como o primitivo natural. É a partir desse raciocínio que Rousseau enfatiza a importância da educação começar desde os primeiros dias de vida da criança. Pois, do contrário, "sentiria o incômodo das necessidades, sem conhecer nem imaginar um meio de atender a elas" (ROUSSEAU, 1995, p. 41), seria um homem-criança sem a mínima capacidade de se orientar sensivel e intelectualmente, já que não teve experiências que lhe proporcionassem esse contato com o mundo. A base desse pensamento vai de encontro com o ideal iluminista de autodeterminação e governo de si mesmo, pois Rousseau, como fundador de uma ideia de formação humana, "está convencido de que a criança aprende melhor e de maneira eficiente se tem a oportunidade de desenvolver suas próprias experiências" (DALBOSCO, 2016, p. 132).

Portanto, nota-se a importância da experiência da criança ao longo de todo o processo de maturação para o pleno desenvolvimento de suas capacidades naturais. Desenvolvimento esse que não pode ser apenas psíquico, porém corpóreo e afetivo. Emílio assemelhar-se-á ao selvagem: "quanto mais seu corpo se exercita, mais seu espírito se ilumina; sua força e sua razão crescem juntas e se ampliam uma pela outra" (ROUSSEAU, 1995, p. 112). A robustez do corpo é fundamental para o vigor do 
espírito, de maneira que a educação deve ensinar a criança a respeitar seus limites, tomando consciência de suas forças. O homem natural era forte, pois não ultrapassava seus limites; não desejava aquilo que sua existência não necessitava e a natureza não podia prover. Emílio será educado com base nesse ideal: conhecer a própria condição; pois ser forte é conhecer e respeitar seus limites (DALBOSCO, 2016, p.135).

\section{CONSIDERAÇÕES FINAIS}

Por fim, conclui-se que Rousseau não se preocupou somente em apontar os efeitos da degeneração humana, pelo contrário, após as evidências expostas no Discurso sobre as ciências e as artes, o filósofo suíço empenha-se em encontrar as causas da perversidade, pois considera que não há um só vicio no coração humano que não se possa dizer como e por onde entrou; no Discurso sobre a origem e os fundamentos da desigualdade entre os homens demonstra que não há desigualdades políticas no estado natural, assim como a primeira forma de comunicação humana é destituída de qualquer racionalidade e sobre a origem das línguas, afirma o filósofo no Ensaio sobre a origem das línguas no qual se fala da melodia e imitação musical que o amor foi o grande inventor da linguagem, não as necessidades. No percurso sistêmico da exposição dos argumentos, busca das origens e reflexões sobre possíveis intervenções, no Emílio ou Da Educação o terceiro passo do genebrino foi expor alternativas para combater o mal instalado no homem e a corrupção das instituições, não sendo possivel reverter o efeito negativo da desnaturação, há que se encontrar um jeito de conviver com os males instituídos: Emílio, o indivíduo à margem, será educado para conhecer a sua própria condição humana, portando, será preparado para suportar os males da sociedade moderna.

\section{REFERÊNCIAS}

CASSIRER, Ernst. A filosofia do iluminismo. Tradução: Álvaro Cabral. Campinas: Editora da Unicamp, 1992.

CASSIRER, Ernst. A questão Jean-Jacques Rousseau. Tradução: Erlon José Paschoal, Jézio Gutierre e revisão da Tradução: Isabel Maria Lourenço. São Paulo: Editora UNESP, 1999.

CERIZARA, Beatriz. ROUSSEAU: a educação na infância. São Paulo: Editora Scipione, 1990.

DALBOSCO, Claudio A. Condição humana e educação do amor-próprio em Jean-Jacques Rousseau. São Paulo: Edições Loyola, 2016.

DALBOSCO, Claudio A. A Educação natural em Rousseau: das necessidades da criança e dos cuidados do adulto. São Paulo: Cortez, 2011.

GUAUTIER, Clermont; TERDIF, Maurice. A pedagogia: teorias e práticas da Antiguidade aos nossos dias. Tradução: Lucy Magalhães, 3 ed. Petrópolis, RJ: Vozes, 2014.

LAUNAY, Michel. Introdução: questão prévia. In: Emílio ou Da Educação. / J.-J. Rousseau. São Paulo: Martins Fontes, 1999.

PRADO Jr, Bento. A retórica de Rousseau e outros ensaios. Org. e apresentação: Franklin de Matos. Tradução: Cristina Prado. São Paulo: Cosac Naify, 2008.

PRADO Jr, Bento. A força da voz e a violência das coisas. In: Ensaio sobre a origem das línguas. Campinas, SP: Editora Unicamp, 1998.

ROUSSEAU, J.-J. As Confissões. Tradução: Wilson Lousada. Vol. único. Rio de Janeiro: Livraria José Olimpo Editora, 1948.

PRADO Jr, Bento. Discurso sobre as ciências e as artes. Tradução: Lourdes Santo Machado. São Paulo: Abril Cultural, 1978a.

PRADO Jr, Bento. Discurso sobre a origem e os fundamentos da desigualdade entre os homens. São Paulo: Abril Cultural, 1978b.

PRADO Jr, Bento. Ensaio sobre a origem das línguas: no qual se fala da melodia e da imitação musical. São Paulo: Abril Cultural, 1978c.

PRADO Jr, Bento. Ensaio sobre a origem das línguas; Discurso sobre a origem e os fundamentos da desigualdade entre os homens; Discurso sobre as ciências e as artes; Prefácio de 
Narciso ou o amante de si mesmo. Tradução: Lourdes Santos Machado; Introdução e notas de Paul Arbousse-Bastide e Lourival Gomes Machado e consultoria de Marilena Chauí. 2. ed. Os Pensadores, São Paulo: Abril Cultural, 1978.

PRADO Jr, Bento. Emílio ou Da Educação. Tradução: Roberto Leal Ferreira. 2a ed. São Paulo: Martins Fontes, 1999.

PRADO Jr, Bento. Emílio ou Da Educação. Tradução: Sérgio Milliet. 3.ed. Rio de Janeiro: Bertrand Brasil, 1995.

SOUZA, Maria das Graças de. História e Declínio: Rousseau. In: Ilustração e história: o pensamento sobre a história no iluminismo francês. São Paulo: Discurso Editorial, 2001.

STAROBINSKI, Jean. Jean-Jacques Rousseau: a transparência e o obstáculo seguido de sete ensaios sobre Rousseau. Tradução: Maria Lúcia Machado. São Paulo: Companhia das Letras, 2011.

\section{Notas}

1 Segundo Starobinski, "a preocupação com a origem desempenha já um papel capital nas obras que constituem o sistema" de Rousseau (2011, p. 371). Portanto, o filósofo não se preocupa apenas em expor os efeitos, porém, preocupa-se fundamentalmente com o estado original das coisas.

2 Por ser uma "obra-fonte", Rousseau mostra a intrínseca e necessária relação entre linguagem e sociedade. Segundo Starobinski, Ensaio e Segundo Discurso, narram uma mesma história sob uma dupla versão: este, "insere a história da linguagem no interior de uma história da sociedade", aquele, o oposto, "introduz uma história da sociedade no interior de uma história da linguagem" (2011, p. 409).3 Em meio à crítica da técnica e da cultura burguesa, Rousseau faz menção ao tema da linguagem pela primeira vez em seus escritos: "vossos filhos ignoram a própria língua, mas falarão outras que em lugar algum se usam; saberão compor versos que dificilmente compreenderão; sem saber distinguir o erro da verdade, possuirão a arte de torná-los ambos irreconhecíveis aos outros [...]” (ROUSSEAU, 1978a, p. 347). A linguagem, assim como o próprio homem, sofre alterações ao longo dos tempos. Alterações não apenas quanto a sua própria natureza, mas também em relação à sua função. Na sociedade burguesa setecentista, a comunicação perdera suas características naturais, passando a ser um instrumento de poder, um meio de aprisionamento da verdade, um ornamento de luxo das sociedades corrompidas.

4 Rousseau acreditava que a história humana é negativa, pois estaria mais para uma história da queda, do que para uma ascensão moral (SOUZA, 2001).

5 Sabendo-se das várias interpretações da história negativa ser absoluta ou não na Filosofia de Rousseau, utiliza-se aqui a interpretação de Starobinski (2011) de uma reforma não da sociedade, porém, do indivíduo a partir do projeto pedagógico, posto que não foram abordados aspectos políticos do novo contrato social rousseauniano nesta investigação. Nesse sentido, entende-se que Rousseau não vislumbra a reforma de sociedades já corrompidas, porém, percebendo o limite de seu projeto pedagógico e a audácia de uma educação de caráter reformadora, ele estabelece princípios norteadores de uma educação formadora do indivíduo que ainda será inserido na sociedade, a saber, a criança. Portanto, para o filósofo, uma sociedade corrompida não poderá voltar a um estado anterior a essa corrupção, visto que todos os hábitos e vícios adquiridos são irreversíveis, no entanto, Starobinski (2011) destaca que é possivel preservar a criança dessa cultura, pode-se conceber uma educação que previna e contrarie a influência malévola de uma sociedade corrompida.

6 Para Dalbosco "os conceitos de estado de natureza e de homem são tomados, portanto, como uma escala, ou seja, como uma ideia reguladora, a partir da qual são avaliadas e confrontadas em seu grau de afastamento ou de proximidade" (2016, p. 52). Desse modo, o estado de natureza serve como parâmetro para a educação de Emílio.

7 Apesar da primeira língua do homem ser universal, ela não é raciocinada. A universalidade da linguagem, refere-se ao poder imediato que ela tem, fazendo-se entender por todos que a escutam. Desse modo, a língua natural aproxima-se muito mais de uma lingua que dar-se 
de modo empírico a uma língua da razão. Como o próprio Rousseau enfatiza no Capítulo II do Ensaio, "não se começou raciocinando. mas sentindo" (1978c, 163), portanto, as primeiras línguas dos homens eram apaixonadas, não raciocinada.

8 Para finalizar a questão da linguagem no Segundo Discurso, Jean-Jacques deixa a reflexão. "Quanto a mim, atemorizado com as dificuldades que se multiplicam e convencido da impossibilidade quase demonstrada de terem podido as línguas nascer e estabelecer-se por meios puramente humanos, deixo a quem o desejar, empreender a discussão desse problema difícil de saber o que foi mais necessário - a sociedade já organizada quando se instituíram as línguas, ou as línguas já inventadas quando se estabeleceu a sociedade?" (ROUSSEAU, 1978b, p. 250).

9 Sobre isso o genebrino aponta. "Seguindo a trajetória dos fatos com base nessas distinções, seria talvez preciso raciocinar sobre a origem das línguas de um modo totalmente diverso do que se fez até hoje (ROUSSEAU, 1978c, p. 163).

10 Interessante perceber a distinção cunhada por Rousseau entre linguagem e língua. À esta, pertence os gestos e gritos que são estritamente naturais do homem primitivo, que é desprovido de outras formas para comunicação, uma vez que a língua primitiva é satisfatória para o estado limitado em que o homem se encontra. Àquela, é consequência da aquisição humana pela ação da perfectibilidade, referindo-se a um estado de certo desenvolvimento das luzes e das faculdades humanas.

11 A crítica a uma sociedade decadente, qual seja, a sociedade burguesa da época da ilustração, ultrapassa os limites da linguagem, transcendendo, chega ao modo como o conhecimento foi construído na Europa até aquele momento. Jean-Jacques Rousseau ataca o centro da epistemologia ocidental; ataca o império do modelo etnocêntrico de verdade que desconsiderava outros modelos. Aparece o Rousseau etnólogo, que ditará as palavras a partir daqui, com base em um novo método antropológico, consequentemente, epistemológico.

12 Emílio ou Da Educação, obra de Jean-Jacques Rousseau de 1762. Na obra o filósofo faz críticas constantes ao modelo meramente instrutivo e propõem um novo modelo de educação baseado formação integral do homem, dando ênfase ao primado da liberdade.

13 A educação setecentista tinha por base a pedagogia jesuita, que desconhecia o conceito de infância, confinando os pequenos em instituições de ensino com métodos medievais e tratando-lhes como adultos em miniatura. Foi contra essa educação bárbara que em 1762, Rousseau lançou o Tratado de Educação, obra que entrou para a história da filosofia e da pedagogia, ao considerar aspectos na formação humana nunca antes visibilizados, criando o conceito de infância e tornando-se um autor revolucionário (CERIZARA, 1990, p. 82).

14 Delimitar todas as características do aluno e de seu preceptor é fundamental para delimitar o tipo de educação própria e necessária a cada indivíduo. Além do que a educação não podendo ser implementada integralmente em todos os lugares/paises, se faz necessário estudar não apenas o indivíduo, como também o lugar, os costumes e a sociedade em que se fomentará a educação, uma vez que é necessário fazer alterações no modelo de educação natural de acordo às necessidades de cada povo.

15 Nota-se que Rousseau utiliza o termo governante para se referir ao preceptor ou mestre. O termo aparece na tradução brasileira do Emílio ou Da Educação de Sérgio Milliet da Bertrand Brasil, de 1995 (3.ed) enquanto que traduções como a da Martins Fontes, edição de 1999 ( $2^{\circ}$ ed) de Roberto Leal Ferreira, optam por utilizar o termo "preceptor" ou "mestre": "a escolha da ama-de-leite é tanto mais importante quanto sua criança não deve ter outra ama além dela, assim como não deve ter outro preceptor" (ROUSSEAU, 1999, p. 38).

16 Na Introdução do Emílio, Michel Launay afirma que a educação de Emílio tem um só objetivo: formar um homem livre, capaz de se defender contra todos os constrangimentos. E, para formar um homem livre, há apenas um meio: trata-lo como um ser livre, respeitar a liberdade da criança. É aqui que se insinua o contrassenso mais grave que se cometeu contra o Emílio: Rousseau, no entanto, tinha tomado bastante cuidado para distinguir o respeito às necessidades naturais da criança, da satisfação dos seus desejos ou de seus caprichos. Os pais fracos, que cedem todos os pedidos do filho, longe de respeitar a sua 
liberdade, corrompem-na; longe de fazer dele um ser livre, submetem-no ás suas fantasias e mais tarde às suas paixões. O mais grave não é que eles próprios se tornem escravos do filho, o pior é que fazem dele um escravo (LAUNAY, 1999, p. XX).

17 Sendo o homem um animal composto, com disposições primitivas e faculdades inativas a serem desenvolvidas - dada a impossibilidade de manterem-se inativas - também é tarefa da educação cuidar do bom desenvolvimento da criança, tendo, portanto, a educação natural duas tarefas: uma de conservar a natureza, outra de bem conduzir a maturação das potencialidades da criança (CERIZARA, 1990).

18 Esta segunda fase, constitui a formação da criança por meio de sua condução instrutiva. Sobre isto, Starobinski expõe que "no Emílio, leremos que é preciso empregar muita arte para impedir o homem social de ser inteiramente artificial. É pelo aperfeiçoamento da cultura (portanto, por uma desnaturação mais aprofundada) que o acordo com a natureza pode ser redescoberto, essa natureza segunda, fruto da arte, não se define mais como um equilíbrio obscuro e instintivo: é esclarecida pela razão, sustentada pelo sentimento moral, que o bruto primitivo nada sabia" (2011, p. 396). Portanto a segunda tarefa da educação, referente à conversão da natureza, sendo ela fundamental para o projeto de educação integral de Emílio.

19 De acordo com Cassirer, a ideia fundamental do Emílio é de que não se deve eliminar nenhuma dificuldade física da aprendizagem do pupilo que se quer educar para a independência da vontade e do caráter - e que não se deve poupa-lo de nenhum sofrimento, esforço ou privação. A única coisa da qual se deva cuidadosamente protege-lo é da imposição violenta da vontade alheia - de um preceito que ele não entende em sua necessidade (1999, p. 612).

20 Cerizara acredita que "o que está subjacente nessa crítica é a convicção de Rousseau que a ação dos educadores junto às crianças tende muito mais a degenerá-las. No decorrer do "Livro segundo", ele aprofunda a crítica do que denominou educação positiva, rechaça essa prática que escraviza a criança às falsas normas sociais e opta, assim, por uma educação da liberdade" (1990, p. 81).

21 A linguagem, assim como o próprio homem, sofre alterações ao longo dos tempos. Alterações não apenas quanto a sua própria natureza, mas também em relação à sua função. $\mathrm{Na}$ sociedade burguesa setecentista, a comunicação perdera suas características naturais, passando a ser um instrumento de poder, um meio de aprisionamento da verdade, um ornamento de luxo das sociedades corrompidas (ROUSSEAU, 1978a).

22 Segundo Rousseau, a comunicação desenvolve-se na mesma medida que o homem e suas relações se aperfeiçoam: "quando as ideias dos homens começaram a estender-se e a multiplicar-se, se estabeleceu entre eles uma comunicação mais íntima, procuraram sinais mais numerosos e uma língua mais extensa; multiplicaram as inflexões de voz, [...]. Exprimiram, pois, objetos visíveis e móveis graças a gestos, e aqueles que atingem a audição, graças a sons imitativos; mas como o gesto só indica os objetos presentes ou fácies de serem descritos e as ações visíveis [...], resolveram então substituí-lo pelas articulações da voz que, sem ter a mesma relação com certas ideias, são mais apropriadas a representa-las como sinais instituídos" (ROUSSEAU, 1978b, p. 248).

$23[\ldots]$ o estado de natureza serve sim, mas de modo muito pontual, como contraponto empírico ao conceito de estado social. Nesse sentido, ele designa um estado pré-social, pré-racional e neutro do ponto de vista moral. O ser humano que nele vive não possui, enfim a ideia de formação, por isso falta-lhe a noção de cultura como força formadora do ser humano, que lhe abriria um universo de possibilidades abertas e flexíveis (DALBOSCO, 2016, p. 55).

24 Rousseau acredita que a linguagem não é o espelho da Razão como pensava Leibniz; porém, a linguagem, seu poder de sedução, é, assim, capaz de inverter o jogo das forças: ela é o próprio lugar da perversão (PRADO JR, 2008, p. 114). Portanto a preocupação rousseauniana com relação à linguagem não é mais sobre se ela representa ou não o objeto, mas o abismo entre gramática e politica; o poder do discurso e a potência da retórica. 